\title{
Effects of Sequential Compression Devices plus pharmacological prophylaxis on Venous Thromboembolism Prevention in Mechanically Ventilated Patients in Trauma Intensive Care Unit
}

\author{
Walaa Ahmed Mohammed ${ }^{1}$, Azza Hamdi El-soussi ${ }^{2}$, Mohammed Mohammed Abd Ellatif ${ }^{3}$, Mervat Anwar AbdEl-Aziz ${ }^{4}$ \\ \& Mogedda Mohammed Mehany ${ }^{5}$ \\ 1. Nursing Specialist at Technical Institution of Nursing, Faculty of Nursing, Assiut University, Egypt. \\ 2. Professor of Critical Care Nursing and Emergency Nursing, Faculty of Nursing, Alex. University, Egypt. \\ 3. Professor of Anesthesia and intensive Care, Faculty of Medicine, Assiut University, Egypt. \\ 4. Assistant Professor in Critical Care Nursing Department, Faculty of Nursing, Assuit University, Egypt. \\ 5. Assistant Professor in Critical Care Nursing Department, Faculty of Nursing, Assuit University, Egypt.
}

\begin{abstract}
Venous thromboembolism (VTE) is one of the most common preventable causes of death in trauma patients. Therefore, mechanical prophylaxes Sequential Compression Devices (SCDs) are important part for prevention of VTE in trauma patient. Aim: to determine the effect of sequential compression devices on venous thromboembolism prevention in mechanically ventilated trauma victim. The Researcher used quasi-experimental research design to conduct this study. This research was performed in the trauma ICU at Assiut University Hospital. Sample: A convenient sample of sixty patients entered to trauma ICU. They were split into two groups at random: in control and study group (30 patients each).Tools: Tool I: Modified patient assessment tool, Tool II: - patients' outcomes Assessment sheet. Results of the present study mentioned that study group subjects had lower incidence of VTE (6.66\% vs 36.7\% among control group), also lower mean length of stay (7 days vs 13.6 days for control group), and lower mean days of MV in study subjects than control group with $\mathrm{P}=0.000$. Conclusion: combination of mechanical and pharmacological prophylaxis help in improve outcomes by reducing incidence of VTE, length of stay and mechanical ventilator days Recommendations: Developing strategies that necessitate training healthcare providers to enhance performance, improve patient' outcomes, and fulfill effectiveness of mechanical prophylaxis devices.
\end{abstract}

\section{Keywords: Venous thromboembolism, Sequential compression \&Outcomes.}

\section{Introduction:}

Venous thromboembolism is potentially lifethreatening event among critically ill trauma patients associated with higher morbidity and mortality rate. Deep venous thrombosis DVT and pulmonary embolism PE are the two types of VTE (Yumoto et al., 2017).

Venous thromboembolism may present clinically silent like DVT, or in the form of PE, which acts as most prevalent third cause of death in traumatic patient that may occur within first 24 hours after trauma. Various risk factors have been reported for developing VTE in ICU trauma patients which include older age, the severity of injuries, pelvic or femur bone fractures, spinal canal injuries, and central venous cannulation, medical comorbidities including DM and obesity bed rest, hematologic cancers, immobilization, Sepsis, vasopressor use, mechanical ventilators, respiratory, cardiac or renal failure (Mowafy et al., 2019).

Venous thromboembolism is a disease where clots are formed in the deep veins, particularly in the veins of the legs. Which result in blockage in blood flow causing manifestations such as discomfort, swelling and skin color change of the affected part. The clots moving into other blood vessels like pulmonary artery, causing pulmonary embolism (Ejaz et al., 2018).

Thromboprophylaxis involve both Pharmacologic and mechanical. For high-risk patients without contraindications, prophylaxis chemically by using enoxaparin or unfractionated heparin should be considered. while prophylaxis mechanical using like intermittent pneumatic compression or compression stockings which decrease clot formation by applying external pressure on blood vessel and pushing blood to flow forward and the endothelium will emit nitric oxide, prostacyclin, and tissue plasminogen activator as a result of the shear and strain pressures. Furthermore, plasminogen activator inhibitor levels are lower. (Park et al., 2016).

Nurses in critical care have significant impact in VTE prevention. Nurses are present with patients when admitted and remain with them during their hospital stay.They are in the best position to identify risk factors and request for VTE prophylaxis as early as 
possible. She must be aware of the risk factors of DVT or PE as well as various therapies utilized to avoid this potentially fatal condition

(Mohammed et al., 2018).

\section{Significance of the study}

Trauma patients are known to be at greater risk for developing venous thromboembolism which associated with increased mortality rate ranges from $13 \%$ to $48 \%$ for DVT and as high as $25 \%$ in case of PE. If thromboprophylaxis is not used the prevalence of VTE in trauma patients can have up to $14 \%$ to $59 \%$ while it was diagnosed in up to $3.6 \%$ to $33 \%$ of severe trauma patients on thromboprophylaxis (Nielsen et al., 2020). The number of patients who have been hospitalized to the trauma ICU and mechanically ventilated was about 480 patients at 2018 (Assuit University Hospital records, 2018).

Aim of the study:

The goal of this research was to determine how sequential compression devices plus anticoagulant affected venous thromboembolism's prevention in mechanically ventilated patients at trauma ICU.

Research hypothesis:

- Hypothesis (1) venous thromboembolism incidence among mechanically ventilated trauma patients who have SCD plus pharmacological prophylaxis is going to be lower than those in the control group.

- Hypothesis (2) mechanically ventilated trauma patients with SCD and pharmacological prophylaxis is going to have shorter ICU stay than those in the control group.

- Hypothesis (3) mortality rate among mechanically ventilated trauma patients who have SCD plus pharmacological prophylaxis is going to be lower than those received only pharmacological prophylaxis.

\section{Subjects and Method}

Research design: the current trial was carried out using a quasi-experimental design.

Setting: The research was executed at Assuit University Hospital's trauma intensive care unit.

Sample: sixty patients were chosen as a convenient sample and randomly allocated to one of two groups: control or study (each has a total of thirty patients).

$$
\begin{gathered}
n=\frac{N Z^{2} 2}{Z^{2}{ }^{2}+N e^{2}} \\
n=\frac{615 \times(1.96)^{2} \times(0.221)^{2}}{(1.96)^{2} \times(0.221)^{2}+615 \times(0.05)^{2}}=60
\end{gathered}
$$

Where:

$Z=1.96[$ standard scores],

$$
\begin{aligned}
& e=0.05 \text { [error] } \\
& =0.221[S D] \\
& N=615[\text { population] }, \\
& n=60 \text { [sample] } \\
& \text { Inclusion criteria: }
\end{aligned}
$$

Patients between the ages of 18 and 60 and recently connected to mechanical ventilator were included to this study.

Exclusion criteria: Excluded from this study patients who have

DVT, bleeding disorder, extremity deformity, and skin breakdown

Tools:-

Data were collected using two tools in order to achieve the aim of this study.

Tool I: Patient Assessment Sheet. It was created by the researcher after a thorough examination of the relevant literature (Petridou \& Antonopoulos, 2017), (Akavipat et al., 2019).It includes the following parts:

Part I: - this section contains Socio demographic (code, age, gender), past medical history, current diagnosis and causes of trauma.

Part two: this part consists of following categories: Acute Physiology and Chronic Health Evaluation II (APACHE II) was adopted from (Akavipat et al., 2019), it is used to assess the severity of illness in the adult ICU patients. It calculates a point score based on the age of patient, long term health problem, and physiological variables, as well as the initial values of twelve routine physiologic measurments (temperature, MAP, pulse rate, breathing rate, oxygenation, arterial $\mathrm{pH}$, sodium, potassium, creatinine, hematocrit, WBCs, and GCS)

Reliability of this score was adopted from (Donahoe et al., 2009) as he reported that APACHE II was very trustworthy (interclass correlation coefficient was 0.88 prior to intervention versus 0.80 after intervention).

Neurological examination: Glasgow Coma Scale that was adopted from (Petridou \& Antonopoulos, 2017). It is utilized to provide a reliable, objective method of documenting a person's conscious state for initial and subsequent assessment. It categoriesed as:

- Severe GCS $\leq 8$

- Moderate GCS 9-12

- Mild GCS $\geq 13$

Reliability of Glasgow Coma Scale (GCS)was adopted from (Reith, et al., 2015). As he cleared that GCS was highly reliable (Eleven research reported Cronbach's alpha values. 100 percent of the six values derived from high quality studies are greater than 0.80).

Second Tool: Patients' Outcomes Assessment Tool: It was created by the researcher after a 
thorough examination of the relevant literature (Urden et al., 2017), ( Lim et al., 2018). and composed of two parts:

Part I: clinical signs \& symptoms compatible with DVT, (calf pain, calf tenderness, warmth of calf muscle, distention of superficial vein, swelling of extremities and skin color changes).

Part II: Adverse events of sequential compression device application as skin breaks, hemodynamic instability, discomfort or calf pain, skin irritation, and pharmacological prophylaxis side effects. D.V.T occurrence concerned with Doppler examination, PE occurrence, and mechanical ventilation days, stay in the ICU, and death rate.

Methods:

The study was carried out on three phases:

Preparatory phase:

1.The researcher created study after conducting review of the literature

2.The researcher received official permission from the chief of the Assuit university hospital's TICU at after explaining the study's purpose and nature.

Content validity: Five jury experts examine the study's tools for content validity. Modifications were made by three members of the critical care nursing team and two members of the anaesthesia and intensive care medical staff.

Pilot study: the practicability and applicability of the tools as well as the time required to gather data was tested in pilot research. The tools were useful, and the pilot research participants $(10 \%=6)$ patients were not included in the main study.

Reliability of the adapted tools had been done after reviewing literatureusing Cronbach's coefficient alpha test as the following

Tool I: part 1 - Socio demographic and clinical data (0.830)

Tool II: patients' outcomes (0.791).

The research was approved by the local ethical council, and it followed standard clinical research ethics guidelines.

Protection of human rights: Each patient or the responsible person in the case of an unconscious patient's gave their informed consent. The researcher highlighted that participation of the patients was optional, and that the data was coded to ensure patient confidentiality and anonymity. The patient was promised that he might leave the study at any moment and for no reason.

\section{Implementation phase}

Data collection started from January 2019 until September 2019 .Patients randomly allocated to one of two groups: control and study

Implementation phase for the two groups: prior to gathering any data, patients' assessment start on the day of admission and tool 1 (part 1) was used to capture their bio-socio-demographic and baseline clinical data from each patient's sheet.

- The researcher determined patients' severity disease by using tool one part 2 (APACH II), and assessed patients' level of conscious by GCS.

- Patient's outcomes (Length of ICU stay, number of days on mechanical ventilation, ICU mortality rate, and the development of venous thromboembolism) by using tool 2 .

Study group: Each patient of the study group patients were have sequential compression device in addition to pharmacological prophylaxis during application of sequential compression device the following step must be considered:

- Prior to placement of SCD sleeves on the patient's leg, baseline skin and neurovascular examination must been completed, documented and repeated every eight hours. Which were included: pain's existence and intensity, pallor, palpable heartbeats, paresthesia, , skin abnormalities beneath the sleeve, rising edema of the extremity, also swelling, redness, discomfort are indicators of potential blood clots in the extremity:.

- Ensure the stocking are securely Wrapped around the leg of the patient

- To guarantee a proper fit, .Put two fingers between the patient's leg and SCD

- Plug the sleeve into the mechanical pump.

- To revise connections, look for the arrows on the pump side and on patient side of pump hose that show proper insertion from the sleeve to the pump

- Turn on the pump and assure that everything is in functioning order.

- stay with patient for one complete cycle of sleeve inflation and deflation

- Take off the sleeve once a day for a brief period of time. every 8 hours and check the extremity's skin integrity and neurovascular condition

- The sleeve should be removed when the patient bathes or walks.

Evaluation phase:

This phase was performed to evaluate effect of applying sequential compression device in addition to pharmacological prophylaxis on preventing venous thromboembolismthrough evaluating the studied patients' outcomes according to their assessment data (Length of ICU stay, number of days on mechanical ventilation, ICU mortality rate, and the development of venous thromboembolism).

\section{Statistical analysis}

All data were recorded in a special chart for every patient. The collected data were coded, analyzed and tabulated .Data entry and analysis were done using SPSS 20.0 statistical software package. For qualitative variables descriptive statistics in the form of frequencies and percentages were used whereas, 
for quantitative variables, means and SD were used. In the event of comparisons between two independent groups, continuous quantitative data were compared using analysis of variance test. Using independent Ttest and chi-square test to determine significant, it is considered significant when $\mathrm{P}$ equal or less than 0.05 significant and non- significant when $\mathrm{P}$ more than 0.05 .

\section{Results}

Table (1): Distribution of personal data in the study \& control groups

\begin{tabular}{|c|c|c|c|c|c|}
\hline \multirow{2}{*}{ Socio-demographic } & \multicolumn{2}{|c|}{$\begin{array}{c}\text { Study } \\
(\mathbf{n}=30)\end{array}$} & \multicolumn{2}{|c|}{$\begin{array}{l}\text { Control } \\
(n=30)\end{array}$} & \multirow[t]{2}{*}{ P-value } \\
\hline & No. & $\%$ & No. & $\%$ & \\
\hline \multicolumn{5}{|l|}{ Sex: } & \multirow{3}{*}{0.222} \\
\hline Male & 21 & 70.0 & 25 & 83.3 & \\
\hline Female & 9 & 30.0 & 5 & 16.7 & \\
\hline \multicolumn{5}{|l|}{ Age: (years) } & \multirow{3}{*}{0.078} \\
\hline Mean \pm SD & \multicolumn{2}{|c|}{$32.73 \pm 12.54$} & \multicolumn{2}{|c|}{$38.37 \pm 13.78$} & \\
\hline Range & \multicolumn{2}{|c|}{$18.0-58.0$} & \multicolumn{2}{|c|}{$20.0-59.0$} & \\
\hline
\end{tabular}

Table (2): Percent distribution of Clinical data in the study \& control groups

\begin{tabular}{|c|c|c|c|c|c|}
\hline \multirow[t]{2}{*}{ Patients' Characteristics } & \multicolumn{2}{|c|}{$\begin{array}{c}\text { Study } \\
(n=30)\end{array}$} & \multicolumn{2}{|c|}{$\begin{array}{l}\text { Control } \\
(n=30)\end{array}$} & \multirow[t]{2}{*}{ P-value } \\
\hline & No. & $\%$ & No. & $\%$ & \\
\hline \multicolumn{5}{|l|}{ Diagnosis on admission } & \multirow{4}{*}{0.498} \\
\hline Head injury & 24 & 80.0 & 20 & 66.7 & \\
\hline Chest trauma & 4 & 13.3 & 6 & 20.0 & \\
\hline Abdominal trauma & 2 & 6.7 & 4 & 13.3 & \\
\hline \multicolumn{5}{|l|}{ Causes of Trauma: } & \multirow{4}{*}{0.498} \\
\hline Motor car accident & 20 & 66.7 & 24 & 80.0 & \\
\hline Falling from height & 6 & 20.0 & 2 & 6.7 & \\
\hline Assault from other & 4 & 13.3 & 4 & 13.3 & \\
\hline \multicolumn{5}{|l|}{ Past medical history: } & \multirow{4}{*}{0.559} \\
\hline Diabetes mellitus & 7 & 23.3 & 9 & 30.0 & \\
\hline Hypertension & 0 & 0.0 & 0 & 0.0 & \\
\hline Others & 23 & 76.7 & 21 & 70.0 & \\
\hline \multicolumn{5}{|l|}{ GCS on admission: } & \multirow{2}{*}{0.062} \\
\hline Mean \pm SD & \multicolumn{2}{|c|}{$9.03 \pm 1.38$} & \multicolumn{2}{|c|}{$9.93 \pm 2.59$} & \\
\hline \multicolumn{5}{|l|}{ APACH II score: } & \multirow{3}{*}{0.596} \\
\hline Mean \pm SD & \multicolumn{2}{|c|}{$20.77 \pm 2.46$} & \multicolumn{2}{|c|}{$21.33 \pm 3.01$} & \\
\hline Range & \multicolumn{2}{|c|}{$17.0-27.0$} & \multicolumn{2}{|c|}{$17.0-30.0$} & \\
\hline
\end{tabular}

Chi-square test \& Independent samples t-test.

* Statistical significant difference $(p<0.05)$

APACHE II score: Acute Physiologic Assessment and Chronic Health Evaluation

GCS: Glasgow Coma Scale 
Table (3): Comparison between the studied groups in relation to laboratory investigation

\begin{tabular}{|c|c|c|c|}
\hline \multirow{2}{*}{ laboratory investigation } & Study $(n=30)$ & Control $(n=30)$ & \multirow{2}{*}{ P-value } \\
\hline & Mean \pm SD & Mean \pm SD & \\
\hline \multicolumn{4}{|l|}{ Partial thrombin time(PT) } \\
\hline $1^{\text {st }}$ day & $14.39 \pm 1.27$ & $14.07 \pm 1.86$ & 0.089 \\
\hline $3^{\text {th }}$ day & $14.16 \pm 1.18$ & $15.43 \pm 2.57$ & $0.037 *$ \\
\hline $7^{\text {th }}$ day & $13.77 \pm 2.24$ & $15.34 \pm 0.72$ & $0.031 *$ \\
\hline $10^{\text {th }}$ day & $13.06 \pm 1.40$ & $13.53 \pm 1.17$ & $0.038 *$ \\
\hline \multicolumn{4}{|l|}{ Platelets: } \\
\hline $1^{\mathrm{st}}$ day & $191.43 \pm 70.10$ & $183.10 \pm 54.30$ & 0.224 \\
\hline $3^{\text {th }}$ day & $239.11 \pm 86.27$ & $187.22 \pm 56.43$ & $0.001^{*}$ \\
\hline $7^{\text {th }}$ day & $299.47 \pm 124.46$ & $193.80 \pm 61.51$ & $0.001^{*}$ \\
\hline $10^{\text {th }}$ day & $316.13 \pm 120.06$ & $196.87 \pm 78.10$ & $0.000^{*}$ \\
\hline \multicolumn{4}{|l|}{ HGB: } \\
\hline $1^{\text {st }}$ day & $9.24 \pm 1.89$ & $9.04 \pm 1.08$ & 0.432 \\
\hline $3^{\text {th }}$ day & $9.46 \pm 1.52$ & $9.30 \pm 0.98$ & 0.348 \\
\hline $7^{\text {th }}$ day & $9.61 \pm 1.26$ & $9.79 \pm 0.92$ & 0.441 \\
\hline $10^{\text {th }}$ day & $10.38 \pm 1.28$ & $10.62 \pm 1.82$ & 0.790 \\
\hline
\end{tabular}

$P>0.05$ not significant $\quad * P<0.05$ significant

\section{venous thromboembolism}

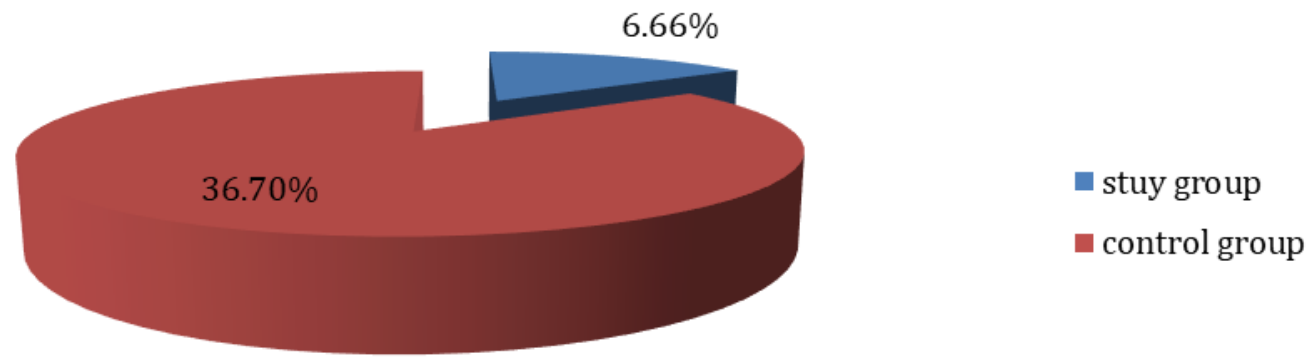

Figure (1): Comparison between both study \& control groups in relation to incidence of venous thromboembolism

Table (4): Percent distribution of DVT manifestations in the study and control group

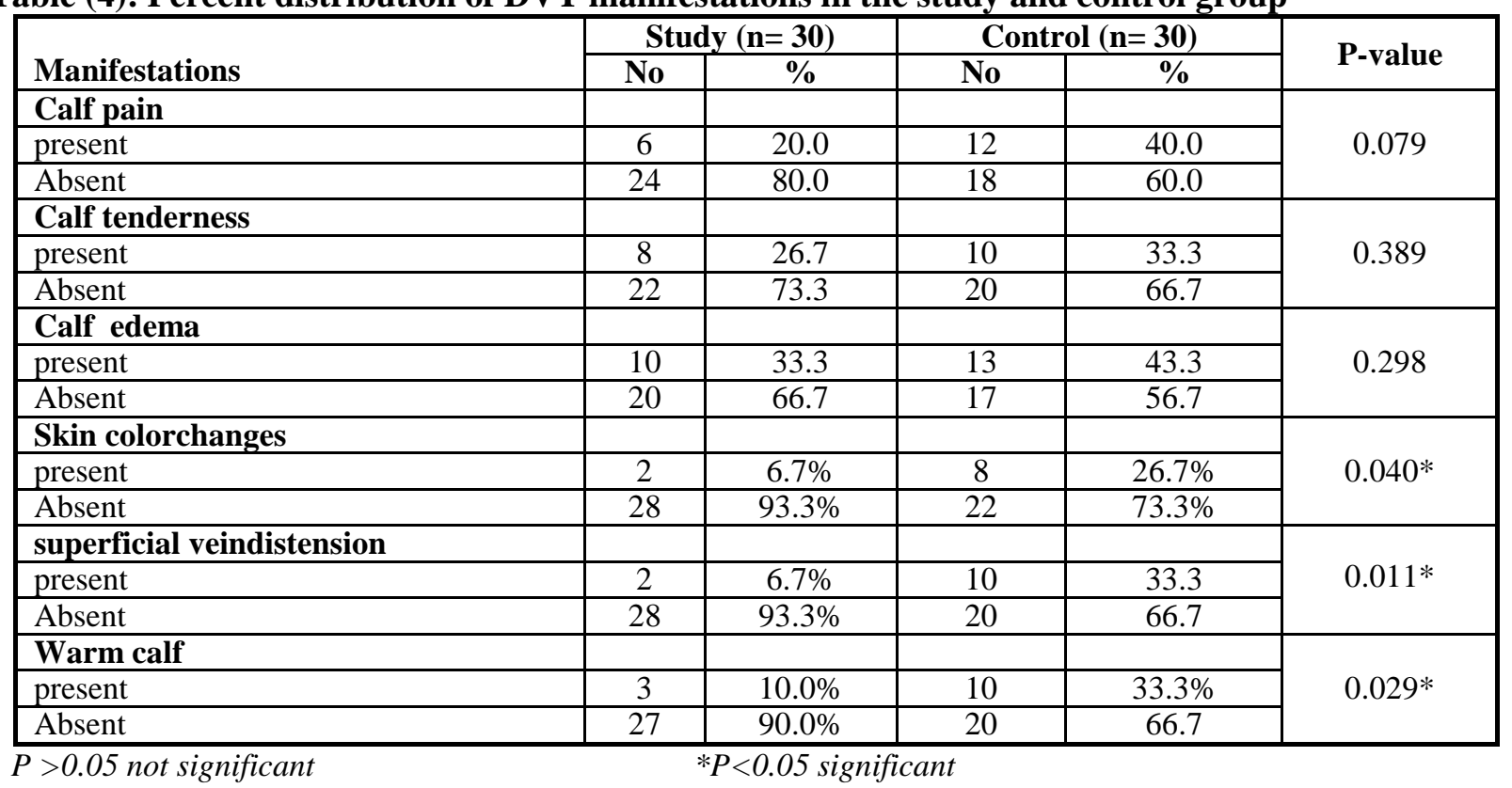


Table (5): Comparison of clinical outcomes in the study and control group

\begin{tabular}{|c|c|c|c|c|c|}
\hline \multirow{2}{*}{ Clinical outcomes } & \multicolumn{2}{|c|}{$\begin{array}{c}\text { Study } \\
(\mathbf{n}=\mathbf{3 0})\end{array}$} & \multicolumn{2}{|c|}{$\begin{array}{l}\text { Control } \\
(\mathbf{n}=\mathbf{3 0})\end{array}$} & \multirow[t]{2}{*}{ P-value } \\
\hline & No. & $\%$ & No. & $\%$ & \\
\hline DVT & 2 & 6.7 & 9 & 30.0 & $0.043^{*}$ \\
\hline Pulmonary embolism & 0 & 0.0 & 2 & 6.7 & 0.472 \\
\hline Adverse event of SCD & 2 & 6.7 & 0 & 0.0 & 0.472 \\
\hline Incidence of bleeding & 1 & 3.3 & 4 & 13.3 & 0.119 \\
\hline ICU mortality & 7 & 23.3 & 8 & 26.7 & 0.766 \\
\hline MV duration(days) & \multicolumn{2}{|c|}{$6.97 \pm 3.00$} & \multicolumn{2}{|c|}{$13.63 \pm 6.26$} & $0.000^{*}$ \\
\hline \multicolumn{5}{|c|}{ ICU length of stay: (days) } & \multirow{3}{*}{$0.000^{*}$} \\
\hline Mean \pm SD & \multicolumn{2}{|c|}{$11.37 \pm 3.48$} & \multicolumn{2}{|c|}{$17.50 \pm 6.03$} & \\
\hline Range & \multicolumn{2}{|c|}{$9-18$} & \multicolumn{2}{|c|}{$14-25$} & \\
\hline
\end{tabular}

Chi-square test \& Independent samples t-test

MV: Mechanical ventilation DVT: Deep venous thrombosis

SCD: sequential compression device

Table (1): Shows in excess of two third of the investigated groups were male ( $70 \%$ of intervention while $83 \%$ of control group), where study group aged from eighteen to fifty-eight years old while control group aged from twenty to fifty- nine yearsold with no significant difference between both groups.

Table (2): Compare the clinical data of the study and control groups. It noted that the most common current diagnosis was head injury follow by chest trauma in the two groups. Also, Majority of intervention and control groups with no comorbidty $(76.7 \%$ vs. $70 \%$ respectively). In addition, the table illustrated that majority oftrauma in both group results from motor car accidents. Also,higher mean of APACHEII score in control group.

Table (3): Illustrates the mean the laboratory tests for the both groups. The mean of the partial thrombin time was found to be higher among control group. there were no significant differences between the two groups in the term of Haemoglobin mean. Also mean of platelets was found to be lower in control group with significant difference from $3^{\text {rd }}$ day.

Figure (1): Illustrates that percentage distribution of venous thromboembolism was higher among control group subject.

Table (4): Presents Percent distribution of DVT manifestations in the studied groups. No significant between both groups in the terms of calf pain, calf tenderness, and calf edema but significant differences were founded between groups in the terms of skin color, distention of superficial veins and warm calf were $(0.040 \& 0.011$ and 0.029 respectively).

Table (5): Illustrates the mean number of days on MV and number of days in ICU was lower in study group than that of control group. Also higher rate of mortality, incidence of DVT and PE present among control group.

\section{Discussion:}

Deep vein thrombosis and pulmonary embolism are two types of VTE, which consider the most preventable event and continue to negatively impact outcomes of trauma patients. VTE caused by three contributing factors (Virchow's Triad) resulting in thrombosis formation include venous stasis, vascular injury, and hypercoagulability (Houghton \& Key. 2017). So, sequential compression device, can decrease thrombus development by reduce venous stasis, improving the speed of blood flow, and increasing the amount of fibrinolysins in the blood (Stone, et al., 2017).

This study shows that two third of the study sample in both group were males, where study group aged from 18- 58years old while control group aged from20- 59years old with no significant difference between them. This finding was confirmed by the finding of Wan, et al., 2015. Who evaluated thromboprophylaxis in critical patient using anticoagulant and IPC

Regarding APACHE II score, the mean of the current study was lower than that in the comparison done by Gaspard, et al., (2015) between various venous thromboembolisms' prophylaxis in mechanically ventilated patients. Also in the same study they reported the most common past medical history were hypertension followed by diabetic mellitus. This is disagreeing with the finding of our study that shows diabetic mellitus was the most common past medical history.

Arabi et al., 2019 reported that the mean APACHE II score among critically ill patients undergoing pharmacologic prophylaxis and IPC was $20.1 \pm 7.8$ versus $20.2 \pm 7.7$ for patients receiving pharmacologic thromboprophylaxis alone.

Regarding clinical signs compatible with DVT among studied patients, the current study found that 
patients with SCD in study group had less DVT signs than patients in the control group with significant differences regarding skin color, distention of superficial veins and warm calf. The researcher thinks that this finding might be due to the effect of compression of the lower vein in the study group subjects which accelerated blood flow and prevent venous stasis and interrupt process of thrombus formation

These results are supported by result of Ead et al., 2016 who evaluate how nursing care standards help in preventing DVT among Patients Undergoing Hip Surgery. However; clinical signs are a much less reliable indication of DVT than is generally believed.This sign may be present in patients with muscle injury or other lower leg disorder without DVT.

Lucia M. et al., 2017reported that Fewer than $20 \%$ of patients with documented DVT have clinical sign. Approximately one-half of patients with clinical signs of DVT have a normal venogram; conversely, more than one-half of documented cases of DVT are not detected clinically. Clinical prediction rules, which made up of combinations of clinical features can be valuable for early dedication of this potentially lifethreatening condition.

As regarded to outcomes (venous thromboembolism, LOS on ICU \& NO. of days on MV, Mortality)

As regarded to incidence of venous thromboembolism (DVT and pulmonary embolism PE), our study shows that patients receiving sequential compression device had lower rate of DVT and pulmonary embolism than control group. As regarded to number of days on MV and number of days in ICU. This study reveals that the mean were lower in study group. The researcher think this could relate to the improvement in circulation achieved by combining mechanical and anticoagulant therapy, resulting in speedy recovery and discharge.

Our study supported by Ley, et al., 2020 who reported that using of mechanical prophylaxis (sequential pneumatic compression) in trauma patients reduce DVT incidence when no pharmacologic prophylaxis is used and is thus advised for those who cannot take pharmacologic prophylaxis.

Ibrahim and colleagues 2015 who study the effect of mechanical prophylaxis on preventing of DVT among trauma patients. The findings showed that DVT incidence reduced after applying of SCDs in trauma patient

According to Zhang et al., 2018, the sequential pneumatic compression group had mortality rate of $10.75 \%$ compared to $12.89 \%$ in the control group.
Also, it was reducing the risk of DVT among study group.

Randomized controlled study conducted by Zhang et al., 2011 who evaluate the use of pneumatic compression to avoid venous thromboembolism reported that study group have a significantly lower rate of DVT (3.80\% vs. $19.28 \%$ in control group with $\mathrm{P}<0.01)$, lower rate of $\mathrm{PE}(0.0 \%$ in study compared to $9.64 \%$ for control group $\mathrm{P}<0.01)$, also shorter duration of MV and ICU stay and lower mortality rate were seen in study group.

Sakai et al., 2016. Reported that the occurrence of PE was $2.92 \%$ in the control group versus $1.20 \%$ in the study group receiving IPC plus chemical prophylaxis. Also lower incidence of DVT in study group

Wang, et al., 2020 Reported reduce incidence of venous thrombosis when use pneumatic compression as thromboprophylaxis in critically ill patients.

Our study agree with finding of Sang, et al., 2018 who reported that combination prophylaxis is superior to monoprophylaxis in decreasing VTE.

Kakkos et al., 2016 intermittent pneumatic compression and anticoagulants prophylaxis were found to be effective in reduce rate of pulmonary embolism and DVT than use pharmacological prophylaxis only about (12-27 and 62 -27per 1000respectively).

Arabi et al., 2019 reported that critically ill patients who were receiving pharmacologic thromboprophylaxis and intermittent pneumatic compression did not result in a significantly lower incidence of proximal lower-limb deep-vein thrombosis than pharmacologic prophylaxis.

Our finding supported by Gaspard, et al., 2015 reported that the mean LOS on ICU \& NO. Of days on MV among patient receiving mechanical Prophylaxis were lower than that in chemical Prophylaxis group.

Our study not supported with Dhakal et al., 2019 who evaluate " preventing VTE by using Sequential Compression Devices in ". They reported that mean length of stay was $7.8 \pm 8.7$ among patient receiving combination of pharmacological and sequential compression versus $6.2 \pm 8$. Also, the study reported that use of Sequential Compression Devices was not associated with decreased VTE incidence.

Regarded intervention related adverse events, our study shows that two patient of study group reported discomfort and pain. The researcher guess that discomfort or pain below compression result from the new experience of 'pressure on the leg' but may also be due to incorrect sizing. Also, there was one occurrence of bleeding in the study group and four cases in the control group. 
Our finding disagree with Dennis., (2013) who reported that one patient had skin breaks as an adverse event of applying intermittent pneumatic compression.

Lim et al., 2018 who investigate whether various methods of pneumatic compression of the lower extremities have different hemodynamic effects. They reported that about six patients receiving sequential pneumatic compression had hemodynamic instability (MAP of $<60 \mathrm{mmHg}$ ).

Wan et al., (2015) reported that the occurrence of bleeding was $5.4 \%$ in the LMWH group while $5.3 \%$ in the LMWH plus intermittent pneumatic compression group where bleeding stopped following drug withdrawal.

\section{Conclusion}

Based on the outcomes of the current research, it's possible toconcluded that patients with combined sequential compression devices and pharmacological prophylaxis had lower incidence of venous thromboembolism, mortality rate, reducing mechanical ventilation days and length of ICU stay.

\section{Recommendations}

The following suggestions are made based on the findings of the current research

- Further researches are recommended to include developed guidelines for mechanical thromboprophylaxis.

- Developing strategies that necessitate training healthcare providers toenhance performance, improve patient' outcomes, and fulfill effectiveness of mechanical prophylaxis devices.

- Future similar studies should be carried on a big sample size in different governmental hospitals for universalization.

\section{References}

- Akavipat, P., Thinkhamrop, J., Thinkhamrop, B., \& Sriraj, W. (2019): Acute Physiology and Chronic Health Evaluation (APACHE) II Score The Clinical Predictor in Neurosurgical Intensive Care Unit, ActaclinicaCroatica, 58(1), 50-56.

- Assuit University Hospital records (2018).

- Arabi YM, Al-Hameed F, Burns KEA, Mehta S, Alsolamy SJ, Alshahrani MS, Mandourah Y, Almekhlafi GA, Almaani M, Al Bshabshe A, Finfer S, Arshad Z, Khalid I, Mehta Y, Gaur A, Hawa H, Buscher H, Lababidi H, Al Aithan A, Abdukahil SAI, Jose J, Afesh LY, \& AlDawood A. (2019): Adjunctive Intermittent Pneumatic Compression for Venous Thromboprophylaxis, N Engl J Med. 4;380(14)1305-1315.
- Dennis, M. (2013): Effectiveness of intermittent pneumatic compression in reduction of risk of DVT in patients who have had a stroke, The Lancet, 382, 516-524.

- Dhakal. P., Wang. L., Gardiner. J., Shrotriya. S., Sharma. M., \& Rayamajhi. S. (2019): Effectiveness of Sequential Compression Devices in Prevention of Venous Thromboembolism in Medically Ill Hospitalized Patients: A Retrospective Cohort Study, Turkish journal of haematology, 36(3), 193-198.

- Donahoe L., McDonald E., Kho M., Maclennan M., Stratford P., \& Cook D, (2009):Increasing reliability of APACHE II scores in medical surgical intensive care unit; Aquality improvement study, American Journal of Critical Care, Volume 18, No. 1, pp. 58 - 64.

- Ead DME., Abd-Allah K., Hegazi MO., \& Mohammed SS. (2016): Effect of Nursing Care Standards for Preventing Deep Vein Thrombosis among Patients Undergoing Hip Surgery on Nurses' Performance and Patients' Outcome, IOSR Journal of Nursing and Health Science e-ISSN: 2320-1959.p- ISSN: 2320-1940 Volume 5, Issue 4 Ver. II . PP 00-00.

- Ejaz. A., Ahmed. M., Tasleem. A., Rafay Khan Niazi. M., Ahsraf. M., Ahmad. I., Zakir. A., \& Raza. A., (2018): Thromboprophylaxis in Intensive Care Unit Patients; A Literature Review. Cureus, 10(9), e3341.

- Gaspard. D., Vito. K., Schorr, C., Hunter. K., \& Gerber. D., (2015): Comparison of Chemical and Mechanical Prophylaxis of Venous Thromboembolism in Nonsurgical Mechanically Ventilated Patients, Thrombosis, 2015, 1-6.

- Houghton.D., \& Key. N., (2017): Venous Thromboembolism, International Encyclopedia of Public Health, 330-336.

- Ibrahim. M., Ahmed. A., Mohamed. W., \& ElSayed Abu Abduo, S. (2015): Effect of Compression Devices on Preventing Deep Vein Thrombosis Among Adult Trauma Patients. Dimensions of Critical Care Nursing, 34(5), 289300

- Kakkos SK, Caprini JA, Geroulakos G, Nicolaides AN, Stansby G, Reddy DJ, \& Ntouvas I. (2016): Combined intermittent pneumatic leg compression and pharmacological prophylaxis for prevention of venous thromboembolism, Issue 9. Art. No.: CD005258.

- Ley, E., Brown, C., Moore, E., Sava, J., Peck, K., Ciesla, D., Sperry, J., Rizzo, A., Rosen, N., Brasel, K., Kozar, R., Inaba, K., \& Martin, M. (2020): Updated guidelines to reduce venous thromboembolism in trauma patients: A Western Trauma Association critical decisions 
algorithm, Journal of trauma and acute care surgery, 89(5), 971.

- Lim H, Kim J, Lee K, Seo D, \& Ko S (2018): Hemodynamic effects of different types of pneumatic compression of the lower extremities during anesthesia induction: a prospective randomized controlled trial Korean J Anesthesiol, Oct; 71(5): 386-393.

- Lucia Mazzolai1, Victor A., Walter A., Giancarlo A., Adriano A., Rupert B., Marjolein P.A., Harry R. Bu“ ller,Antoine E., Dominique F., Stavros K., Gualtiero P., Paolo P., Marc R., Adam T.,Vlachopoulos, \& Marianne B.(2017): Diagnosis and management of acute deep veinthrombosis, European Heart Journal 0,1-13.

- Mohammed AS, Taha., \& AbdElAziz EM. (2018): Nurses' Performance Regarding Venous Thromboembolism Prophylaxis at Intensive Care Unit,Zagazig Nursing Journal, Vol. 14, No.1

- Mowafy AA., AttiaSM, Awad MA, Alghandour M, AbdEIghani MA \& El Said M (2019): Risk Factors of Venous Thromboembolism in Polytrauma Patients: A Single Centre Report. Acta Scientific Orthopaedics, 2(6), 02-11.

- Nielsen S, O'Connor D, Kaul S, Sharma J, Napolitano M, Simonian G, Blatt M, Zielonka T, Nyirenda T, \& Cohn S.(2020): Early Detection of Deep Venous Thrombosis in Trauma Patients,Cureus, 12(7) e9370.

- Park, J., Lee, J., Lee, J., \& Cho, Y. (2016): Pharmacological and Mechanical Thromboprophylaxis in Critically Ill Patients: a Network Meta-Analysis of 12 Trials, Journal of Korean Medical Science, 31(11), 1828.

- Petridou, E., \& Antonopoulos, C. (2017): Injury Epidemiology, International Encyclopedia of Public Health, 258-274.

- Reith, F. Van den Brande, R., Synnot, A., Gruen, R., \& Maas, A. (2015): The reliability of the Glasgow Coma Scale, a systematic review. Intensive Care Medicine, 42(1), 3-15.

- Sakai T, Izumi M, Kumagai K, Kidera K, Yamaguchi T, Asahara T, Kozuru H, Jiuchi Y, Mawatari M, Osaki M, Motokawa S, \& Migita K (2016): Effects of a foot pump on the incidence of DVT after total knee arthroplasty in patients given edoxaban: a randomized controlled study. Medicine (Baltimore); 95(1):e2247.

- Sang, C. Q., Zhao, N., Zhang, J., Wang, S. Z., Guo, S. L., Li, S. H., Jiang, Y., Li, B., Wang, J. L., Song, L., Zhai, J. J., \& Zhang, Z. Y. (2018): Different combination strategies for prophylaxis of venous thromboembolism in patients: A prospective multicenter randomized controlled study, Scientific reports, 8(1), 8277.
- Stone, J., Hangge, P., Albadawi, H., Wallace, A., Shamoun, F., Knuttien, M., Naidu, S., \& Oklu, R. (2017): Deep vein thrombosis: pathogenesis, diagnosis, and medical management. Cardiovascular diagnosis and therapy, 7(Suppl 3), S276-S284.

- Urden DL, Stacy MK, \& Lough EM: (2017), critical care nursing, diagnosis and management, $8^{\text {th }}$ Edition chapter 15 cardiovascular disorders, pages 399-402

- Wan, B., Fu, H., Yin, J., \& Ren, G. (2015): Low-molecular-weight heparin and intermittent pneumatic compression for thromboprophylaxis in critical patients, Experimental and therapeutic medicine, 10(6), 2331-2336.

- Wang, Y., Huang, D., Wang, M., \& Liang, Z. (2020): Can Intermittent Pneumatic Compression Reduce the Incidence of Venous Thrombosis in Critically Ill Patients: A SystematicReview \&Meta-Analysis. Clinical and Applied Thrombosis/Hemostasis, 26, 10.

- Yumoto, T., Naito, H., Yamakawa, Y., Iida, A., Tsukahara, K., \& Nakao, A. (2017): Venous thromboembolism in major trauma patients: a single-center retrospective cohort study of the epidemiology and utility of D-dimer for screening. Acute medicine \& surgery, 4(4), 394400.

- Zhang D, Li F, Li X, \& Du G. (2018): Effect of Intermittent Pneumatic Compression on Preventing Deep Vein Thrombosis Among Stroke Patients: A Systematic Review, Worldviews Evid Based Nurs. Jun; 15(3):189-196.

- Zhang C, Zeng W, Zhou H, Zheng B, Cheng J, Li X, Jiang Y, \& Jiang L (2011):Efficacy of intermittent pneumatic compression in the prevention of venous thromboembolism in medical critically ill patients, Sep;23(9):563-5. 